\title{
TERTMAN RIZIKA U COSO SISTEMU INTERNE KONTROLE
}

\section{Mile Stanišić ${ }^{1}$ Siniša Janković, Nikola Škobo ${ }^{2}$}

1 Univerzitet Singidunum, Beograd, Srbija

2Univerzitet Sinergija, Bijeljina, Republika Srpska, BiH

\begin{abstract}
Apstrakt:
Rizik se definiše kao mogućnost da će se neki događaj negativno odraziti na postizanje ciljeva. Ocenjivanje rizika predstavlja dinamičan iterativan proces za utvrđivanje i ocenjivanje rizika koji se odnose na postizanje ciljeva. Preduslov za ocenjivanje rizika je utvrđivanje ciljeva, koji su povezani na različitim nivoima entiteta. Menadžment utvrđuje ciljeve u okviru kategorija koje se odnose na poslovanje, izveštavanje i usaglašenost sa zakonima i propisima, dovoljno precizno da bi se mogli identifikovati i analizirati rizici tih ciljeva. Takođe, menadžment razmatra koliko su postavljeni ciljevi odgovarajući za entitet.
\end{abstract}

Ključne reči:

COSO, interna kontrola, procena rizika, upravljanje rizikom.

\section{UVOD}

Jedna od najvažnijih kategorija svake organizacije je interna kontrola, koju uspostavlja i ocenjuje menadžment, a interna i eksterna revizija daju svoje uveravanje o njenoj efektivnosti. Prema članu 54 Zakona o tržištu kapitala, eksterna revizija mora dati mišljene o upravljanju rizicima, internim kontrolama i internoj reviziji. Stoga se nameće ključno pitanje - koliko menadžeri razumeju sistem interne kontrole, kao i pravilnost validacije njene efektivnosti od strane eksterne revizije, i pravilnost korišćenja COSO modela interne kontrole pri njenoj proceni. Interna kontrola je sastavni deo upravljanja rizicima, ali i sama struktura interne kontrole prema COSO okviru u sebi ima komponentu „Procena rizika“. U ovom radu cilj je bio da se istraži struktura te komponente, kako se proverava njeno postojanje i efikasnost funkcionisanja, kao i kako ova komponenta doprinosi potpunoj efikasnosti interne kontrole u postizanju ciljeva entiteta. Predstavljena su četiri principa procene rizika sa fokusnim tačkama vezano za svaki princip. Posebno su istaknute izmene Procene rizika u COSO smernicama iz 2013. godine. Takođe, prema COSO okviru, ukratko je predstavljena struktura celog sistema interne kontrole. Treba napomenuti da je zbog pristupa Evropskoj uniji javni sektor Republike Srbije najdalje otišao u primeni COSO modela.

\section{RAZUMEVANJE COSO SISTEMA INTERNE KONTROLE}

Postoji više okvira interne kontrole, američki (COSO), kanadski (CoCo), britanski (Cadbury, TurnBull Report) i dr., ali svetski standard predstavlja COSO okvir. Odmah se postavja pitanje - šta znači akrinom COSO? Komitet sponzorskih organizacija Tredvej komisije - COSO (Committee of Sponsoring Organizations) je osnovan 1985. godine kao sponzor National Commission on Fraudelent Financial Reporting, po nezavisnoj incijativi privatnog sektora, u kojoj su proučeni uzročni faktori koji mogu da vode ka lažnom finansijskom izveštavanju. Takođe, u njoj su date preporuke za javne kompanije, njihove nezavisne revizore za U.S. SEC (U.S. Securities and Exchange Commission), druga regulatorna tela i obrazovne institucije. Zajednički je finansira pet značajnih profesionalnih 
asocijacija sa sedištem u SAD: American Accounting Association (AAA), American Institute of Certified Public Accountants (AICPA), Financial Executives International (FEI), Institute of Internal Auditors (IIA) i Institute of Management Accountants (IMA) (COSO, 2015).

Prvi COSO okvir interne kontrole objavljen je 1992. godine i nije se menjao punih 20 godina. Novi odnosno izmenjeni okvir je objavljen tek 2013. godine. Pošto pomaže naporima organizacijama da razviju ekonomične/efikasne sisteme interne kontrole za postizanje značajnih poslovnih ciljeva koji održavaju i unapređuju poslovanje, novi okvir predstavlja značajan razvoj. On takođe pomaže organizacijama da se prilagode sve većoj kompleksnosti i dinamici promenljivog poslovnog okruženja, da upravljaju rizicima do prihvatljivih nivoa i da unapređuju pouzdanost informacija za odlučivanje.

COSO definiše internu kontrolu kao proces koji obavljaja bord direktora, menadžment, i ostalo osoblje entiteta koje treba da obezbedi razumno (objektivno) uveravanje u pogledu postizanja ciljeva koji se odnose na poslovanje, izveštavanje, i usaglašenost sa zakonima i propisima. COSO najbolje objašnjava funkcionisanje sistema interne kontrole putem kocke. Kocka se vrlo malo menjala od 1992. godine, samo je prikazan obrnut redosled komponenti interne kontrole. Na slici 1 prikazana je struktura kocke.

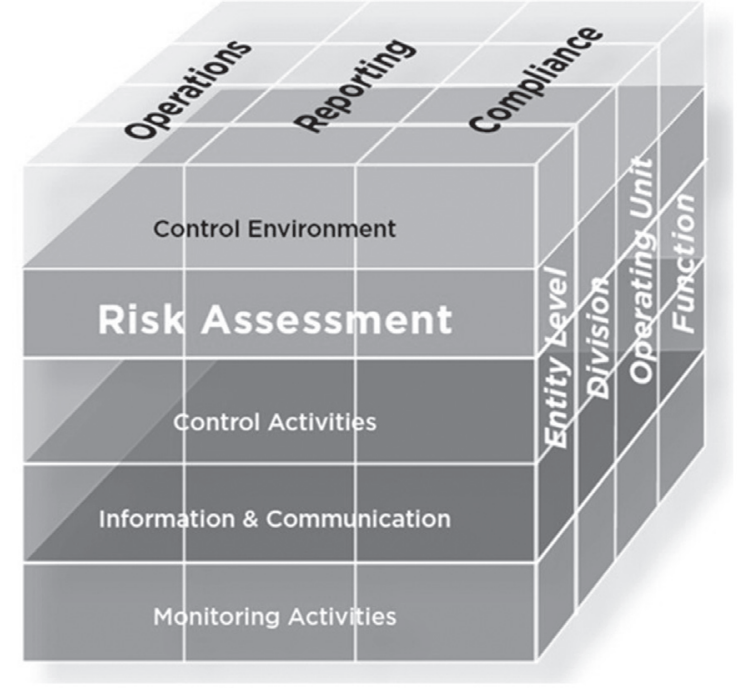

Slika 1. Struktura COSO kocke

Izvor: COSO Internal Control: Integrated Framework 2013

Kocka počinje sa ciljevima na vrhu koji se odnose na poslovanje, izveštavanje, i usaglašenost sa propisima koji predstavljaju kolone kocke. Svaka organizacija utvrđuje relevantne ciljeve i formuliše strategije i planove za njihovo postizanje. Kao što je prikazano, strana kocke označava da se ciljevi mogu utvrđivati za entitet kao celinu, ili za specifična odeljenja, operativne jedinice i funkcije u okviru entiteta (uključujući poslovne procese kao što su prodaja, nabavke i proizvodnja), ilustrujući hijerarhijsku strukturu od vrha prema naniže kod većine organizacija.
Na prednjoj strani kocke se nalazi pet komponenti interne kontrole, koje predstavljaju redove kocke. Slično okviru iz 1992. godine, ove komponente pomažu naporima organizacije da ostvari svoje ciljeve. Ovih pet komponenti su: kontrolno okruženje, ocenjivanje rizika, kontrolne aktivnosti, informacije i komunikacije, i aktivnosti monitoringa. One su relevanthe za celi entitet, što znači da funkcionišu na nivou entiteta, kao i na nivou svih odeljenja, operativnih jedinica, funkcija, supsidijarnih organizacija ili drugih podgrupa entiteta.

Kocka opisuje direktan odnos između ciljeva organizacije (koji predstavljaju ono što entitet nastoji da postigne); komponente interne kontrole (koje predstavljaju ono što je potrebno da bi se postigli ciljevi); i operativne jedinice, pravne entitete i druge strukture u okviru entiteta (koji predstavljaju nivoe organizacije gde pet komponenti interne kontrole funkcioniše). Svaka komponenta interne kontrole se primenjuje na sve tri kategorije ciljeva.

\section{PRINCIPI PROCENE RIZIKA}

COSO smernice koje se odnose na komponentu ocenjivanja rizika pružaju odličnu mogućnost za definisanje i ostvarivanje značajnih ciljeva kompanije, koji se odnose na poslovanje, izveštavanje i usaglašenost sa zakonima i propisima. Za neke kompanije COSO smernice, i povezanost sa postojećim procesom strateškog planiranja koje one zahtevaju, mogu znatno da promene način na koji one upravljaju poslovanjem, kreiraju operativnu efikasnost i čak povećavaju profitabilnost. Prema COSO, postoje četiri principa koji se odnose na komponentu ocenjivanja rizika:

\section{Princip 6}

Organizacija određuje ciljeve dovoljno precizno (jasno) da bi se omogućilo utvrđivanje i ocenjivanje rizika koji se odnose na ciljeve.

\section{Princip 7}

Organizacija utvrđuje rizike za ostvarivanje ciljeva i analizira rizike kao osnovu za izbor adekvatnog načina upravljanja rizicima.

\section{Princip 8}

Organizacija razmatra mogućnosti prevara prilikom ocenjivanja rizika za postizanje ciljeva.

\section{Princip 9}

Organizacija utvrđuje i ocenjuje promene koje bi mogle značajno da utiču na sistem interne kontrole.

\section{PRINCIP 6: JASNO DEFINISANJE CILJEVA}

Preduslov za ocenjivanje rizika je utvrđivanje ciljeva, koji su povezani sa različitim nivoima entiteta. Ovi ciljevi su usklađeni i podržavaju ispunjavanje strateškog smera entiteta. Ovim principom se postavlja osnova za ocenjivanje rizika. $\mathrm{Za}$ 
neke kompanije ovo može predstavljati oblast za razmatranje unapređenja procesa i odgovarajuće dokumentacije. Obično je potrebno da kompanija opiše ciljeve koji se odnose na poslovanje, izveštavanje (eksterno finansijsko, eksterno nefinansijsko, interno) i usaglašenost sa zakonima ipropisima. U COSO smernicama se navodi: "Mada postavljanje strategija i ciljeva ne predstavlja deo procesa interne kontrole, ciljevi čine osnovu na kojoj se pristupi ocenjivanja rizika primenjuju i obavljaju i na kojoj se utvrđuju sledeće kontrolne aktivnosti." (COSO, 2013, str. 42).

Kao deo interne kontrole, menadžment određuje ciljeve i grupiše ih u šire kategorije na svim nivoima entiteta koje se odnose na poslovanje, izveštavanje i usaglašenost sa zakonima i propisima. Grupisanje ciljeva u okviru ovih kategorija omogućava da se identifikuju i ocene rizici za postizanje tih ciljeva. Prilikom razmatranja prikladnosti ciljeva i strateških prioriteta, menadžment treba da istraži sledeća pitanja:

- Usklađenost ciljeva i strateških prioriteta;

- Utvrđivanje tolerancije rizika za ciljeve;

- Usklađenost između utvrđenih ciljeva i utvrđenih zakona, pravila, propisa i standarda koji se primenjuju u entitetu;

- Utvrđivanje ciljeva korišćenjem termina koji su specifični, mogu se oceniti ili pratiti, mogu se postići, relevantni su i vremenski ograničeni;

- Utvrđivanje ciljeva entiteta i njegovih podjedinica;

- Usklađenost ciljeva sa drugim okolnostima koje zahtevaju posebnu pažnju entiteta;

- Odobravanje ciljeva u okviru procesa postavljanja ciljeva.

Tamo gde su ciljevi u okviru kategorija nejasni, tamo gde je nejasno kako oni podržavaju strateški pravac, i tamo gde postoji zabrinutost da ciljevi nisu odgovarajući na bazi činjenica, okolnosti i utvrđenih zakona, pravila, propisa i standarda koji se primenju u entitetu, menadžment obaveštava o ovoj zabrinutosti radi uključivanja u proces postavljanja strategija i ciljeva.

\section{Ciljevi poslovanja}

Ciljevi koji se odnose na zahteve eksternog finansijskog izveštavanja su u fokusu eksternih revizora i finansijskog osoblja kompanije. Važno je da menadžment bude energičan u definisanju ciljeva svih kategorija organizacije. Definisanje ciljeva poslovanja može da bude posebno dragoceno. Tačke na koje se treba fokusirati u vezi sa ciljevima poslovanja, mogu doprineti boljem upravljanju i smanjenju rizika kompanije. Zaista, sa operativne tačke gledišta one mogu da budu značajne koliko i ciljevi koji se odnose na rizik finansijskih izveštaja.

Razvoj i primena ciljeva poslovanja su bitni za obavljanje strateškog planiranja, koje nekim kompanijama jako nedostaje. Za mnoge firme, posebno velike kompanije koje već imaju snažan i zdrav proces strateškog planiranja, nove smernice za ocenjivanje rizika mogu imati veoma malo uticaja. Mnoge firme srednje veličine, a posebno start-up firme, nisu razvile jake procese strateškog planiranja. Te kompanije bi mogle da imaju koristi od utvrđivanja dovoljno jasnih ciljeva, da bi identifikovale i ocenile rizik.

\section{Ciljevi izveštavanja}

Okvir iz 1992. godine se primenjivao na razne oblike izveštavanja koji ne pripadaju eksternom finansijskom izveštavanju. Međutim, sa usvajanjem SOA (Sarbanes-Oxley act), i odgovarajućih pravila SEC-a (Securities and Exchange Commission), COSO okvir interne kontrole je postao usko povezan sa eksternim finansijskim izveštavanjem (McNally, 2013, str. 18). Okvir iz 2013. godine detaljno opisuje upotrebu smernica za druge situacije, koje nastaju prilikom izveštavanja, kako bi se obezbedio kontekst za širu primenu komponenti i principa.

Ciljevi izveštavanja se odnose na sastavljanje izveštaja koji obuhvataju pouzdanost, pravovremenost, transparentnost ili druge uslove utvrđene od strane regulatornih tela, tela za postavljanje standarda ili politikama entiteta. Ova kategorija obuhvata eksterno finansijsko izveštavanje i eksterno nefinansijsko izveštavanje. Ciljevi eksternog izveštavanja se postavljaju u skadu sa zakonima, pravilima, propisima i standardima koje utvrđuju vlade, regulatorna tela, tela za postavljanje standarda i računovodstvenih tela. Ciljevi internog izveštavanja su postavljeni u skladu sa strateškim upravljanjem entiteta, i izveštavanjem o zahtevima i očekivanjima menadžmenta i borda direktora.

\section{Ciljevi koji se odnose na usaglašenost sa zakonima i propisima}

Sledeće tačke na koje se treba fokusirati mogu da pomognu menadžmentu da utvrdi da li je ovaj princip usvojen i da li funkcioniše, pošto se odnosi na ciljeve usaglašenosti, tj. ispunjava zakone i propise:

- Odražava eksterne zakone i propise - Zakonima i propisima se utvrđuje minimum standarda o ponašanju, koje entitet integriše u ciljeve koji su usaglašeni sa zakonima i propisima.

- Razmatra toleranciju rizika - Menadžment razmatra prihvatliive nivoe razlika (odstupanja) koji se odnose na postizanje ciljeva usaglašenosti sa zakonima i propisima.

Zakonima i propisima je utvrđen minimum standarda ponašanja koje entitet integriše u svoje ciljeve koji se odnose na usaglašenost sa zakonima i propisima. Politike i procedure bi se zatim bavile programima informisanja, inspekcijama na licu mesta, i obukom koja bi se odnosila na ciljeve usaglašenosti entiteta sa zakonima i propisima. Slično ciljevima eksternog izveštavanja, menadžment razmatra prihvatljive 
nivoe odstupanja u poslovanju, u kontekstu usaglašenost sa zakonima i propisima. Takvi zakoni i propisi mogu prouzrokovati da menadžment postavi niže nivoe prihvatljivih odstupanja, da bi zadržao usaglašenost sa tim zakonima i propisima.

Entiteti moraju upravljati svojim aktivnostima, i često preduzimaju specifične akcije u skladu sa primenjenim zakonima i propisima. Kao deo utvrđivanja ciljeva za usaglašenost sa zakonima i propisima potrebno je da organizacija upozna zakone i propise koje će primenjivati u entitetu. Mnogi entiteti će utvrditi sledeće ciljeve:

- Sprečavanje i otkrivanje kriminalnog ponašanja i drugih prestupa.

- Sastavljanje i dostavljanje poreskih prijava pre poslednjih rokova za dostavljanje, u skladu sa regulatornim zahtevima.

\section{PRINCIP 7: IDENTIFIKOVANJE I ANALIZIRANJE RIZIKA NA NIVOU ENTITETA}

U skladu sa smernicama iz 1992. godine u fokusu je rizik na nivou transakcije, tj. rizici u procesima koji se obavljaju na operativnom i funkcionalnom nivou. Dajući veću težinu riziku na nivou entiteta, Okvir iz 2013. godine ističe organizacione ciljeve. Štaviše, ovaj pristup zahteva da se rizik prati stalno, a ne jedanput godišnje.

Princip 7 se koristi da bi se odgovorilo na sledeća pitanja:

(1) Koji su rizici za postizanje ciljeva utvrđeni Principom 6 na raznim nivoima entiteta - supsidijarnim oganizacijama (filijalama), odeljenjima, operativnim jedinicama i funkcijama - kao i u samom entitetu?

(2) Koja je verovatnoća da će nastati specifičan rizik; koliko ozbiljan bi mogao da bude; koliko brzo će uticati na kompaniju i koliko dugo?

(3) U slučaju njegovog nastajanja, kako menadžment treba da odgovori? Postoje četiri vrste odgovora (reagovanja): prihvatanje, izbegavanje, smanjenje i podela rizika.

Prema COSO smernicama iz 2013. godine sledeće tačke na koje se treba fokusirati mogu pomoći menadžmentu prilikom odlučivanja o prisutnosti i funkcionisanju ovog sistema:

- Obuhvata entitet, filijale, odeljenja, operativne jedinice i funkcionalne nivoe. Organizacija utvrđuje i ocenjuje rizike na nivoima entiteta, filijala, odeljenja, organizacionih jedinica i funkcija koje su relevantne za postizanje ciljeva.

- Analizira interne i eksterne faktore. Prilikom utvrđivanja rizika razmatraju se interni i eksterni faktori i njihov uticaj na postizanje ciljeva.

- Obuhvata odgovarajuće nivoe menadžmenta. Organizacija uvodi efikasne mehanizme za ocenjivanje rizika koji obuhvataju odgovarajuće nivoe menadžmenta (upravljanja).
- Ocenjuje značaj utvrđenih rizika. Utvrđeni rizici se analiziraju kroz proces koji obuhvata procenjivanje potencijalnog značaja rizika.

- Utvrđuje kako da odgovori na rizike. Ocenjivanje rizika obuhvata razmatranje kako treba upravljati rizicima i da li prihvatiti, izbeći, smanjiti ili podeliti rizik.

Utvrđivanje i analiziranje rizika je stalni iterativan proces koji se obavlja da bi se unapredila sposobnost entiteta da postigne svoje ciljeve. Iako entitet ne navodi eksplicitno sve ciljeve, to ne znači da postoji neki prećutni (koji se podrazumeva) cilj bez internog ili eksternog rizika. Bez obzira da li je neki cilj naveden ili se podrazumeva procesom ocenjivanja rizika entiteta, potrebno je razmotriti moguće rizike. Ovaj proces podržavaju razne aktivnosti, tehnike i mehanizmi koji su relevantni za ukupno ocenjivanje rizika. Menadžment razvija i primenjuje kontrole koje se odnose na obavljanje takvih aktivnosti.

Menadžment razmatra rizike na svim nivoima entiteta i reaguje na njih preduzimanjem potrebnih akcija. Prilikom ocenjivanja, entitet razmatra faktore koji utiču na ozbiljnost, brzinu i postojanost rizika, verovatnoću gubitka sredstava, i odgovarajući uticaj na poslovanje, izveštavanje i usaglašenost aktivnosti sa zakonima i propisima. Takođe, potrebno je da entitet upozna mogućnost prihvatanja rizika i poslovanja u okviru nivoa tih rizika.

Utvrđivanjem rizika se razmatraju rizici na raznim nivoima organizacione strukture, obuhvatajući ceo entitet i njegove podjedinice, i uključujući procese kao što su: prodaja, ljudski resursi, marketing, proizvodnja i nabavka. Utvrđivanje rizika na nivou entiteta se po pravilu obavlja na relativno visokom nivou iuglavnom ne obuhvata ocenjivanje rizika na nivou transakcija. Suprotno tome, utvrđivanje rizika na nivou procesa je po svojoj prirodi detaljnije i uključuje rizike na nivou transakcija. Pored toga, ocenjivanjem se razmatraju rizici koji potiču od spoljnih provajdera usluga, ključnih dobavljača i partnera posrednika koji direktno ili indirektno utiču na postizanje ciljeva entiteta.

Menadžment razmatra rizike koji se odnose na interne i eksterne faktore. Na nivou entiteta rizici mogu biti rezultat eksternih ili internih faktora. Eksterni faktori mogu da obuhvataju: ekonomske promene, prirodno okruženje, regulatorne promene, poslovanje u stranim zemljama, socijalne promene i tehnološke promene.

Interni faktori obuhvataju: infrastrukturu, upravljačku strukturu, kadrove, pristup sredstvima i tehnologiju.

Utvrđivanje eksternih i internih faktora koji doprinose riziku na nivou entiteta je značajno za temeljno i sveobuhvatno ocenjivanje rizika. Kada se jednom utvrde važniji faktori, menadžment može da razmotri njihovu relevantnost i značaj i, ukoliko je moguće, poveže ove faktore sa specifičnim rizicima i aktivnostima. Naravno, smernice COSO daju uputstva za rizike na nivou transakcija. 
PRINCIP 8: RAZMATRANJE MOGUĆNOSTI

ZA PREVARE PRILIKOM OCENJIVANJA RIZIKA ZA POSTIZANJE CILJEVA

Ovim principom se razmatra kako bi prevare mogle sprečiti entitet da postigne ciljeve utvrđene Principom 6. Na osnovu ovog principa, menadžment obavlja ocenjivanje koje razmatra lažno izveštavanje, moguć gubitak sredstava i korupciju, kao posledice raznih načina ostvarenja prevare i kršenja dužnosti (neprofesionalno ponašanje). Prilikom razmatranja zahteva novog principa, kompanije mogu usvojiti različite pristupe.

"Ilustrativni alati" koje je COSO objavio nude korisne preporuke, među kojima se izdvajaju sledeće:

1) Oceniti rizik od prevara, kako bi se utvrdili razni načini na koje se mogu dogoditi prevare.

Menadžment treba da razmotri:

- nivo procena i mišljenja u eksternom finansijskom izveštavanju;

- metodologiju za evidentiranje i obračunavanje nekih računa, kao što su računi zaliha;

- planove i scenarija prevara koje su uobičajene za određenu industrijsku delatnost i tržišta u kojima kompanija posluje;

- geografske regione u kojima kompanija posluje;

- prirodu automatizacije;

- neuobičajene i složene transakcije koje su podložne značajnom uticaju menadžmenta;

- transakcije u poslednjem momentu.

2) Razmotriti pristup koji bi pojedincima u firmi omogućio da zaobiđu ili izbegnu kontrole prevara.

3) Razmotriti rizik od prevara u planu interne revizije.

4) Analizirati pritisak i stimulans koji omugućava prevare u programima nagrađivanja menadžmenta i zaposlenih.

\section{PRINCIP 9: UTVRDITI I OCENITI PROMENE KOJE BI MOGLE ZNAČAJNO DA UTIČU NA SISTEM INTERNE KONTROLE}

Ovaj princip uslovljava stalno ocenjivanje promena (na eksternom i internom planu) koje bi mogle da utiču na rizik. Eksterne promene obuhvataju promene u ekonomskom, regulatornom i fizičkom okruženju. Interne promene obuhvataju promene u poslovnim linijama, inostranim tržištima i poslovanju, novim tehnologijama, kao i promene u liderstvu i filozofiji kompanije.

COSO okvir detaljno definiše tačke na koje se treba fokusirati, a koje mogu da pomognu menadžmentu da utvrdi da li je ovaj princip prisutan i da li funkcioniše:
- Ocenjuje promene u eksternom okruženju. U procesu utvrđivanja rizika razmatraju se promene u regulatornom, ekonomskom i fizičkom okruženju u kojem entitet posluje.

- Ocenjuje promene u poslovnom modelu. Organizacija razmatra potencijalne uticaje novih poslovnih linija, značajno promenjenog sastava postojećih poslovnih linija, proširenih ili odbačenih poslovnih funkcija koje se odnose na sistem interne kontrole, naglog rasta, promene oslanjanja na inostrana geografska područja, i nove tehnologije.

- Ocenjuje promene u liderstvu. Organizacija razmatra promene u upravljanju i odgovarajućim stavovima, mišljenjima i filozofijama koje se odnose na sistem interne kontrole.

\section{ZAKLJUČAK}

Svaki subjekat se suočava sa spoljnim i unutrašnjim rizicima koji se moraju oceniti. Preduslov ocene rizika je utvrđivanje ciljeva koji su povezani na različitim nivoima i interno konzistentni. Procena rizika je identifikacija i analiza relevantnih rizika u odnosu na ostvarenje ciljeva, stvaranjem osnove za utvrđivanje načina upravljanja rizicima. Pošto će se ekonomski, industrijski, i regulatorni uslovi poslovanja i dalje menjati, potrebni su mehanizmi za identifikaciju i bavljenje posebenim rizicima vezanim za promene.

Okvirom iz 2013. godine COSO uvodi 17 principa interne kontrole. Svaki princip se odnosi na jednu od pet komponenti i svaki princip obuhvata više tačaka na koje se treba fokusirati. Na komponentu procene rizika se odnose principi 6, 7, 8 i 9. Kako bi entitet mogao da zaključi da ima efikasnu internu kontrolu, neophodno je prisustvo i funkcionisanje svih relevantnih principa Okvira iz 2013. godine. Principi omogućavaju efikasno funkcionisanje pet komponenti interne kontrole i celog sistema interne kontrole. Da bi se pokazalo da je princip prisutan i da funkcioniše, organizacija mora da shvati cilj i primenu principa; da pomogne osoblju da razume i konzistentno primenjuje princip u entitetu; i da sagleda slabost ili odsustvo principa, što zahteva pažnju menadžmenta.

\section{LITERATURA}

COSO. (1992). Internal Control - Integrated Framework, AICPA. Preuzeto sa http://www.coso.org/ic.htm

COSO. (2013a). Internal Control Integrated Framework 2013. Preuzeto sa http://www.coso.org/ic.htm

COSO. (2013b). Illustrative Tools for Assessing Effectiveness of a System of Internal Control and the Internal Control over External Financial Reporting: A Compendium of Approaches and Examples. Preuzeto sa http://www.coso.org/ic.htm

COSO. (2013c). Internal Control - Integrated Framework, AICPA. Preuzeto sa http://www.coso.org/ic.htm 
COSO. (2015). History. Preuzeto 12.3.2019. sa http://www.coso. org/aboutus.htm

McNally, J.S. (2013). The 2013 COSO Framework and SOX Compliance. Preuzeto sa http://www.coso.org/documents/coso $\% 20$ mcnallytransition $\% 20$ article-final $\% 20$ coso $\% 20$ version $\% 20$ proof_5-31-13.pdf

\section{THE TREATMENT OF RISK IN INTERNAL CONTROL COSO SYSTEM}

\section{Abstract:}

Risk is defined as the possibility of an event to happen and therefore reflect in a negative way on the goals achievement. Risk evaluation is the dynamic and iterative process used for risk identification and risk assessment that impact an objective. Precondition for the risk assessment is the identification of objectives which are connected at different entity levels. The management identifies the objectives within different categories related to business. Also, management identifies reporting and strict compatibility with the law and regulations in order to identify and assess the risks of those objectives. The management also discusses how suitable those objectives are for the entity.

\section{Keywords:}

COSO,

internal control, risk evaluation, risk management. 